
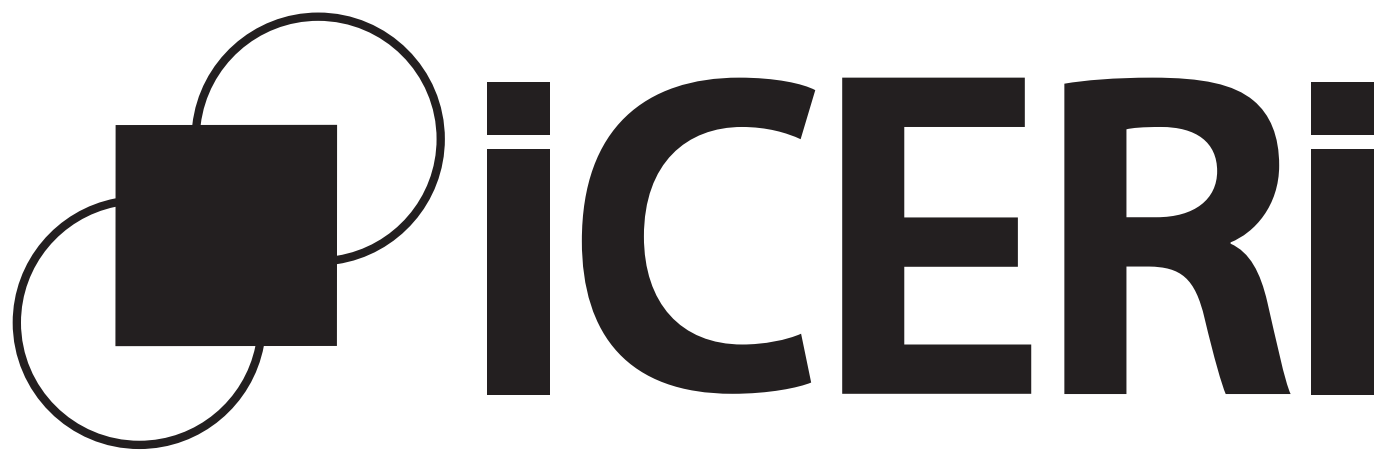

2020

13TH INTERNATIONAL CONFERENCE OF EDUCATION,

RESEARCH AND

INNOVATION
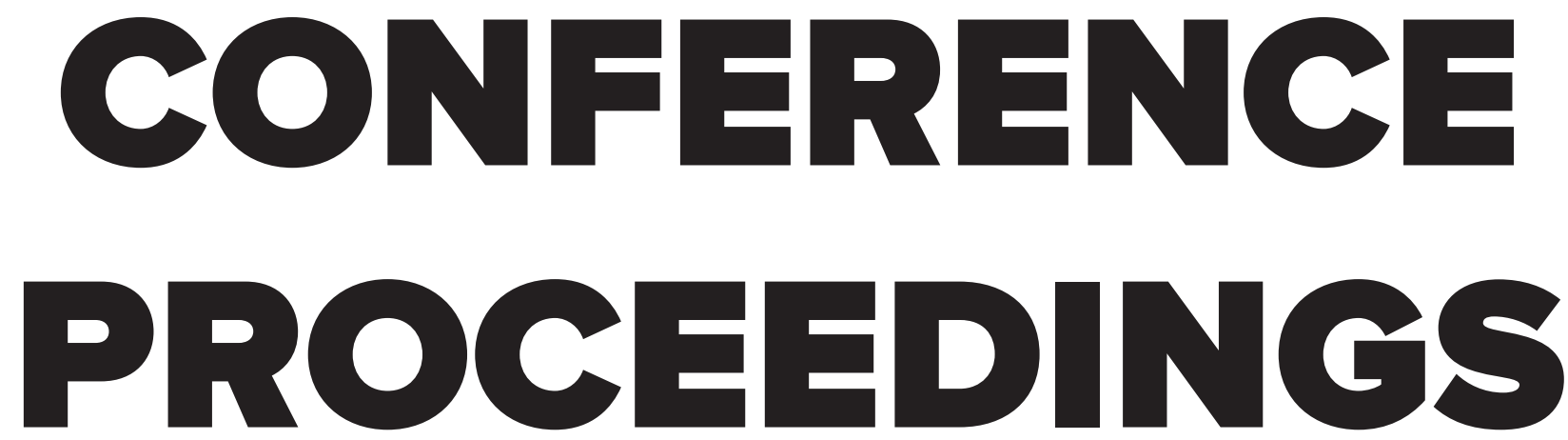

9-10 NOVEMBER 2020 iated.org/iceri 
Published by

IATED Academy

iated.org

\section{ICERI2020 Proceedings}

13th International Conference of Education, Research and Innovation

November 9th-10th, 2020

\section{Edited by}

L. Gómez Chova, A. López Martínez, I. Candel Torres

IATED Academy

ISBN: 978-84-09-24232-0

ISSN: $2340-1095$

V- 2372-2020

Book cover designed by

J.L. Bernat

All rights reserved. Copyright (C) 2020, IATED

The papers published in these proceedings reflect the views only of the authors. The publisher cannot be held responsible for the validity or use of the information therein contained. 


\title{
FROM FACE-TO-FACE TO ONLINE LEARNING: COVID-19 AND THE EMERGENCE OF UBIQUITOUS LEARNING SCENARIOS
}

\author{
Mónica Aresta ${ }^{1}$, Anabela Fernandes ${ }^{2}$, Ana Isabel Ribeiro ${ }^{2}$ \\ ${ }^{1}$ DigiMedia, Department of Communication and Art, University of Aveiro (PORTUGAL) \\ ${ }^{2}$ CEIS20, Faculty of Arts and Humanities, University of Coimbra (PORTUGAL)
}

\begin{abstract}
The Covid-19 pandemic and the declaration of a state of emergency in Portugal triggered a sudden shift to the digital environment. As schools closed on March 16 2020, there was the need to go digital, a leap that had deep impacts not only in learning and education but also in the lives of parents and teachers. More than redesigning pedagogical materials, adapt evaluation systems and learn to use online platforms, shifting to digital revealed disparities on teachers and parents' digital literacy and brought challenges to their professional and personal lives. This paper introduces the first stage of a study that aims to address the main challenges faced by Portuguese Primary and Secondary Education teachers and parents with children on those levels of education, during the period of suspension of classroom activities (from 16 March to 30 June 2020). Data was collected through semi-structured individual interviews made to teachers and parents $(\mathrm{N}=22)$. Preliminary data indicates that the digital adaptation required significant adjustments and challenges, such as negotiation between personal and professional life, coping with the loss of face-to-face interaction, managing time and physical space, and keeping children interested and motivated during the confinement period. When digital transition is seen as something that requires more than just an adaptation to the online environment, this paper describes the ubiquitous learning scenarios that emerged during COVID-19 confinement period, presenting and proposing a reflexion about the challenges faced by all educative agents - schools, teachers, parents and students.
\end{abstract}

Keywords: Covid-19 pandemic, Ubiquitous learning scenarios, digital transition, learning process, settings and constrains, parents, teachers.

\section{INTRODUCTION}

As technological development eased the access to information, ubiquitous learning - technologically mediated learning that occurs regardless of time and space - provides learning experiences that can happen at any time, anywhere, and in various ways [1], [2], [3]. Ubiquitous learning has the potential to overcome geographical barriers and reach a wider audience, levelling the field for students generally disadvantaged in access to education [4], [5], [6]. With the growing popularity of technology-based learning that takes place in online environments, challenges faced by the different educational actors start to emerge. Educational Institutions are required to optimise the logistic dimension of learning namely the efficiency of online platforms. Teachers have to adapt their teaching strategies, including the adaptation of pedagogical practices and assessment models. As for students, moving online requires the existence or development of skills related with autonomy and responsibility for their own learning goals, time management, self-assessment and critical thinking, competencies that may not be yet fully developed. Moreover, it is important not to ignore factors that are not under direct control of the Educational Institutions: the different personal characteristics of the learners, the technological infrastructure (i.e. ease or difficulty in accessing to technology), socio-demographic and economic factors, teachers, parents and learners capacity for self-motivation, organisation and self-discipline factors that often condition the success of an online learning strategy [7].

The Covid-19 pandemic and the declaration of a state of emergency in Portugal triggered a sudden shift to the digital environment. In this paper, it is described the first stage of a study aiming to characterize the ubiquitous learning scenarios and challenges brought by the COVID-19 pandemic to the Portuguese Primary and Secondary Education context. Exploratory empirical research addressing the main challenges experienced by Primary and Secondary school teachers, and parents with children in those levels of education, during the period of suspension of classroom activities was carried out, aiming to answer the following questions: 1) during the period of suspension of classroom activities, what were the main challenges you had to face as a teacher/parent?; 2 ) in what concerns time management, what were the main challenges of working from home?; 3 ) while using technology to support the teaching and 
learning process, what were the main pedagogical and emotional challenges you had to address?; 4) while working from home, what strategies had to be adopted to reconcile and/or articulate the personal and professional dimensions of your live?; and 4) in what concerns privacy and online exposition, what were the challenges of dealing with yours/your children'/students' online exposure?. Data was collected through individual interviews made to teachers and parents ( $\mathrm{N}=20$, convenience sampling).

This paper presents the main results of this study and it is organised as follows: following introduction, Section 2 contextualizes the study and provides an overview of the Portuguese education scenario during the suspension of classroom activities. Section 3 describes the methodological approach adopted in the study. Section 4 discusses the main results and findings, and presents a reflection on the main dimensions to be considered in the transition to computer mediated education. The paper ends with conclusions (Section 5) and concluding remarks which propose a reflection on the challenges posed by the integration and assimilation of technology, by individuals, in the personal, professional and affective dimensions of their lives.

\section{BACKGROUND: THE PORTUGUESE CONTEXT}

With the Covid-19 pandemic and the declaration of a state of emergency in Portugal, and with schools closing on March 16 2020, there was the need to go digital, a leap that had deep impacts not only in learning, education but also in the lives of individuals. A preliminary report of a study aiming to understand the impact of Covid-19 pandemic in the Portuguese teaching system [8] points out that, by the early days of April, $5^{\text {th }}$ to $9^{\text {th }}$ grades' students (convenience sampling) mentioned preferring study at school, as it was before the declaration of the state of emergency. Missing friends, colleagues and teachers and being able to communicate with teachers in an easier way are the main reasons pointed by students to prefer face-to-face learning, also mentioning that it was easier to learn when at school. As for the ones who preferred online learning, the flexibility in managing time, being in a more comfortable physical space and not being conditioned to follow the classroom discipline and rules were mentioned by $1 / 4$ of the respondents as main the main reasons. A second partial report [9] was released on 4 May 2020, presenting the results of a questionnaire applied to a sample of 1754 individuals on the first day of the third term, after Easter holidays (i.e. 6 April 2020). Asked to give their opinion on the impact of school closures on equal opportunities for access to education, $64.1 \%$ of respondents said that closing schools affected students learning, especially those with fewer resources. Of the respondents, $7.3 \%$ think that the closure of schools has not hindered equal opportunities for access to education, as it was possible to compensate for the different material living conditions of families.

Moving to a model of teaching and learning supported and mediated by technology, even considering the wide coverage of the Internet in Portugal (in March 2020, 81.5\% of households in Portugal had access to broadband Internet), was not an easy and linear process. The results of a study that gathered answers from 2647 teachers from different teaching cycles [10], reported that almost all teachers $(98 \%)$ said they were sending work to their students, clarifying doubts via the Internet $(90.5 \%)$ and teaching classes using videoconferencing platforms $(87.7 \%)$. In the same report, teachers mentioned to be working an additional 11 hours per week. As for parents, the need to support their children and the security and safety measures implemented by employers implied a shift to remote working; when asked about future plans regarding work, and already knowing that schools would be closed until the end of the school year for children up to grade 10 [11], 38\% of a 2230 parents sample said that in the near future they would be working remotely so they could support their children, who would not be returning to school.

\section{METHODOLOGY}

\subsection{Study design}

Aiming to identify the main challenges faced by teachers and parents during the period of suspension of classroom activities, semi structured individual interviews were conducted with teachers from Primary and Secondary Education (grades 1 to 12) and parents with children attending those same levels of education ( $\mathrm{N}=22$, convenience sampling). After a brief introduction where the main goals of the study were addressed, participants were asked to report themselves to the time during which classroom activities were suspended (i.e. from May $16^{\text {th }} 2020$ to $30^{\text {th }}$ June 2020) and answer the following question: during the period of suspension of classroom activities, what were the main challenges you had to face as a teacher/parent? 
After this question was answered, the following sub-questions were placed: in what concerns time management, what were the main challenges of working from home?; while using technology to support the teaching and learning process, what were the main pedagogical and emotional challenges you had to address?; while working from home, what strategies had to be adopted to reconcile and/or articulate the personal and professional dimensions of your live?; and in what concerns privacy and online exposition, what were the challenges of dealing with yours and your children'/students' online exposure? Interviews took between 16 and 32 minutes, and were made between July and August 2020 (i.e., after school year was over and before a new school year begun).

\subsubsection{Ethical consideration}

All participants (convenience sampling) were individually invited by e-mail. A brief contextualization of the study was provided, and permission to record the interview was asked. It was assured that only the main researcher would have access to the video files, and that the research team would have access to the anonymized transcriptions, where personal information was removed and names were replaced with letters ("T" for teachers and "P" for parents). Personal information was limited to age, work modality during the suspension of classroom activities, grade and subject they were teaching (only for teachers), if they had children attending Primary or Secondary Education, and if they were working/attending a rural or urban school. All participants gave their consent for the recording, after which the interviews, made through Zoom, began.

\subsection{Participants}

\subsubsection{Teachers}

12 individual interviews with Primary and Secondary Education teachers were conducted. Teachers were aged between 43 and 58 years old and 8 had children attending school (primary or secondary). 9 taught in schools in urban areas and 3 in rural areas. The detailed teachers' characterization is presented in Table 1.

Table 1. Teachers characterization

\begin{tabular}{l|c|l|c|c|c}
\hline \hline & Age & \multicolumn{1}{|c|}{ Grade(s) } & Subject(s) & $\begin{array}{c}\text { W/school-aged } \\
\text { children }\end{array}$ & $\begin{array}{c}\text { School } \\
\text { location }\end{array}$ \\
\hline T1 & 43 & $4^{\text {th }}$ (Primary Education) & All & Yes & Rural area \\
\hline T2 & 45 & $1^{\text {st }}$ (Primary Education) & All & Yes & Urban area \\
\hline T3 & 45 & $3^{\text {rd }}$ (Primary Education) & All & Yes & Rural area \\
\hline T4 & 49 & $5^{\text {th }}$ (Primary Education) & Visual Arts & Yes & Urban area \\
\hline T5 & 50 & $5^{\text {th }}$ (Primary Education) & History/ Geography & No & Urban area \\
\hline T6 & 56 & $8^{\text {th }}$ and $9^{\text {th }}$ (Secondary Ed.) & Chemistry/Physics & Yes & Urban area \\
\hline T7 & 45 & $7^{\text {th }}$ (Secondary Education) & English & No & Rural area \\
\hline T8 & 49 & $9^{\text {th }}$ to $12^{\text {th }}$ (Secondary Ed.) & Portuguese/English & Yes & Urban area \\
\hline T9 & 58 & $10^{\text {th }}$ to $12^{\text {th }}$ (Professional Ed.) & Tech/Arts & No & Urban area \\
\hline T10 & 48 & $12^{\text {th }}$ (Professional Education) & ICT & No & Urban area \\
\hline T11 & 49 & $11^{\text {th }}-12^{\text {th }}$ (Secondary Ed.) & Philosophy & Yes & Urban area \\
\hline T12 & 49 & $11^{\text {th }} / 12^{\text {th }}$ (Professional Ed.) & Graphic Arts & Yes & Urban area \\
\hline \hline
\end{tabular}

\subsubsection{Parents}

10 individual interviews with parents with children attending Primary and Secondary Education were conducted. Parents were aged between 35 and 45 years old, 7 had children attending Primary Education and 3 had children attending Primary and Secondary Education. 8 attended schools in urban areas and 2 in rural areas, and 2 had children attending private schools. 9 worked remotely during the confinement period. The detailed parents' characterization is presented in Table 2. 
Table 2. Parents characterization

\begin{tabular}{|c|c|c|c|c|}
\hline & Age & Grade attended by children & Worked remotely & School / location \\
\hline $\mathrm{P} 1$ & 43 & $3^{\text {rd }}$ (Primary Education) & Yes & Public, urban area \\
\hline $\mathrm{P} 2$ & 37 & $4^{\text {th }}$ (Primary Education) & Yes & Public, urban area \\
\hline P3 & 45 & $4^{\text {th }}$ (Primary Education) & Yes & Private, urban area \\
\hline P4 & 39 & Pre-school and $1^{\text {st }}$ (Primary Ed.) & Yes & Public, urban area \\
\hline P5 & 35 & Pre-school, $1^{\text {st }}$ and $4^{\text {th }}$ (Primary Ed.) & Yes & Public, rural area \\
\hline P6 & 44 & $1^{\text {st }}$ and $4^{\text {th }}$ (Primary Education) & Yes & Public, rural area \\
\hline P7 & 38 & $5^{\text {th }}(2$ children, Primary Ed.) & Yes & Public, urban area \\
\hline P8 & 45 & $3^{\text {rd }} / 7^{\text {th }}$ (Primary/Secondary Ed.) & Yes & Public, urban area \\
\hline P9 & 44 & $3^{\text {rd }}, 8^{\text {th }}$ and $10^{\text {th }}$ (Primary/Sec.Ed.) & No & Public, urban area \\
\hline P10 & 43 & $2^{\text {nd }} / 10^{\text {th }}$ (Primary/Secondary Ed.) & Yes & Private, urban area \\
\hline
\end{tabular}

\subsection{Content analysis}

After interviews were transcribed and taking as a starting point the thematic units that were the basis of the questions asked to participants (i.e. main challenges faced during confinement time, challenges in time management, challenges in the use of technology, reconciliation between personal and professional life, and management of privacy and online exposure), the transcriptions were thoroughly read (what Bardin, 1977 [12],calls floating reading) and the ideas expressed by the participants were associated with each dimension. After this first codification, the content associated with each of the thematic units was analyzed. The common points identified in the participants' speeches are presented in the following section.

\section{RESULTS}

All interviews started with the aforementioned non-specific question: "during the period of suspension of classroom activities, what were the main challenges you had to face as a teacher/parent?", after which more specific questions - addressing time management, the use of technology, reconciliation between professional and personal life and privacy and online exposition - were made. The main ideas addressed by teachers and parents are summarized in the following sub-sections. Ideas are presented in the order they've emerged, and not by the number of times they were mentioned by the interviewees.

\subsection{Main challenges faced by teachers during the suspension of classroom activities}

\subsubsection{The loss of face-to-face interaction}

The loss of face-to face interaction and its emotional and pedagogical implications were mentioned by 8 teachers.

Pointing out that Primary Education is based on proximity and direct interaction with students, Primary Education teachers stated that going digital required a considerable effort in adapting teaching methodologies and in finding ways to cope with the absence of students: "I missed my students, I missed being with them. Our teaching is based on proximity, touch, direct interaction with the students. We are shaped to teach that way, and the first two adaptation weeks were hard to cope with" (T1); "The way I work and see teaching is through contact, traditional, proximity, being close to the student, understanding the difficulties, looking at the class context as a context of various realities with which one must know how to deal. And it is more difficult to do this from a distance" (T3); "They were not always cooperative, sometimes they did not want to show themselves. And l've missed the look, the touch, the personal contact" (T5).

The loss of physical contact was as source of distress and anxiety, mostly in the first two adaptation weeks. Not being able to see the students, missing colleagues and co-workers was mentioned by 4 teachers as one of the main challenges of teaching and working from home. Stating that the computer is a machine - one that allows the connection between people, but still a machine, a curtain that keeps 
things from flowing, T5 mentioned to have worked overtime as a way to mitigate loneliness: "The first 15 days were distressing, I missed my colleagues and my students". T7 stated that "The school is made up of people, of students", making the loss of eye contact, affection and human relationships dimensions hard to deal with.

Responding to the pedagogical challenges brought by the absence of face-to-face presence required teachers to adapt their teaching strategies and explore new was to keep their students interested, motivated and able to keep up with the school subjects. T3 made use of a physical whiteboard, placed in front of the computer camera, which was used to write and make schemes, thus replicating the classroom's whiteboard. T6 recurred to online tools such as Zoom to create a whiteboard to share with his students, which allowed them to work on reasoning and calculus exercises, and recorded several videos handling instruments and performing chemical experiences: "it was a way to allow students to follow the experience, step-by-step, even if they could not perform it".

The concern about keeping students interested in the online classroom activities was also addressed: "there was the need to find a way to keep students interested along the 60 minutes online class, and to define new evaluation methodologies" (T7); "at first computers were a challenge, but with time the interest was lost" (T5), "it was very difficult to teach without being there" (T10); "The total cut in face-toface communication forced me to reinvent myself" (T11). Acknowledging the fact that many students attended classes through mobile phones, and therefore had no conditions to manipulate or interact with graphic edition online tools, T12 made significant adaptations to the class's programme, working on creativity by exploring the viewing of documentaries and organising visits to virtual museums: "the hands-on part of was lost, but they had more time to think, to explore and to develop their creativity skills".

\subsubsection{The need to quickly adapt to new online platforms}

All teachers mentioned that the need to move and adapt new online platforms was a challenge, for them and for their students. T1, T2, T8, T11 and T12 mentioned that the need to adapt to online teaching implied training and an effort to adapt to new digital platforms they were not familiar with - an effort that was shared with some of their student's parents: "Some parents were not familiar with online platforms, so there was an additional effort to make sure that no student was left behind" (T1). "Easter holidays were used to organise, meet and establish the work plan" (T12). Addressing the parent's effort in supporting their children, one teacher mentions that "parents support was crucial: they attended classes, worked with their children after classes, parents were really committed and collaborative" (T2).

Concerns about the different conditions and support students had in their own homes was a subject addressed by several teachers. Acknowledging that many parents did not have that same computer literacy, T1 was concerned that no student was left out of the online classroom activities and established a communication backchannel with parents (via WhatsApp) to provide technological support during online sessions. T3, already familiar with online teaching platforms, was mostly concerned on how to make sure that all students had the conditions needed to attend online classes and keep working. T9 and T10 sought to ensure that everyone was able to connect with the online platform, to receive information and to answer the new learning challenges brought by the remote learning model.

Moving to online learning requires an additional set of skills and literacies. To T4, $5^{\text {th }}$ grade students still lack autonomy and initiative and sometimes tried to comply with the minimum, so there was the need to ensure that they were able to use the School's platform. T5, stating that "there was no option but to use the computer to teach and learn", was mainly concerned on how to captivate her students' interest. T6 was careful about not overloading students with work, as they do not have the work rhythm of an adult: "e-learning is for adults. Society isn't prepared for young students to be the center of their own learning. Learning is a process, it needs guidance". Digital literacy was addressed by T7, who felt that her students ( $7^{\text {th }}$ grade) matured in terms of attitude and behaviour throughout the period of remote classes: "Characteristics that are part of the XXI student's profile were developed - a forced development, needed under the conditions, but still a forced development". Institutional support, either by the organization of training sessions, tutorials and an Online Education Support Team are mentioned by four teachers: "moving online was eased by the School's training activities, which included tutorials for both teachers and parents" (T2); "the school developed tutorials, institutional e-mails were created and a Distance Learning Support Team was organized, allowing older teachers to overcome digital literacy difficulties" (T7); "the School's support as one of main reasons for the ease adaptation to online teaching" (T8); "lots of things were eased by the School's support" (T9). 


\subsubsection{Overcoming technological infrastructures and equipment barriers}

During the period of suspension of classroom activities, many teachers recurred to their own computers and Internet to keep working: "We gave everything: the internet, the house, the time, the computer" (T4). Teachers and students had to use their own personal equipment to lecture and attend classes, a situation that revealed several disparities and that was an additional source of anxiety: "The school to a certain way levels the inequalities, even artificially. Now these difficulties were clearly visible, it was a period of much anguish" (T2). Overcoming the instability of home internet connection, which revealed to be insufficient for professional use, and concerns about their students' own internet connection and equipment/absence of equipment were points addressed by nine teachers (T1, T2, T4 to T8, T10, T12).

\subsubsection{Managing professional and personal life}

Reconciling professional and personal lives was also seen a challenge faced during the suspension of classroom activities. Some teachers felt the need to work overtime, either to assist students whose parents had difficulties in accessing online platforms or the Internet (T1), to adapt to students' own schedule so they all could progress at the same pace $(\mathrm{T} 3, \mathrm{~T} 8)$, or to adapt teaching strategies and materials (T1, T2, T4, T12). According to teachers, this situation - although necessary - was very demanding and a source of exhaustion.

Working from home also led to challenges in what concerns physical space management and professional and personal contexts separation: "Home became an office where four people were working while trying to keep it a family space"(T1); "the kitchen became my classroom" (T3); "everything happened in the living room" (T10); "I felt that my space was invaded, and the house had to gain many valences" (T11).

Although sometimes it was good to work from home, "a more pleasant and comfortable physical space" (T6), working and living in the same space made it difficult to concentrate and to be productive (T10) and eventually led to a scenario where professional and personal contexts overlapped: "all evolved around school, and it was difficult to reconcile everything" (T8); "sometimes, contexts overlapped" (T7), and "there was no longer a separation between personal and work space" (T12).

Not going out to work also made it difficult to maintain leisure routines which were usually interspersed with moments of professional activity (T2, T11), and to establish a separation between work and family time: "there was the need to articulate between teaching time and household tasks time, and separation between what was professional and what was personal blurred" (T4); "the main personal challenges were to manage school time and household chores, and to deal with all the requests I've received from students, colleagues and friends" (T10).

\subsubsection{The need to re-establish and maintain contact}

With the suspension of classroom activities, there was the need to establish additional communication channels between school, teachers, students and parents. As the second term of schooling was still ongoing, this was a process that reunited the concerns of many schools and teachers: "we were worried about our students, we needed to know if they could follow classes and had the necessary equipment" (T7).

T9 stresses out that the main the main concern and challenge was to keep contact with students and to assure that everyone was able to connect with the online platform. As she verified that most students were more available later in the morning, synchronous sessions were moved to $12 \mathrm{a} . \mathrm{m}$. The teacher was always available, even after traditional working hours, and assignments' feedback was given within a short time - so that students felt that the teacher was there and that they were not alone. Nevertheless, and despite her and her school's efforts, two students did not end the school year: "I consider it a failure, we were unable to transmit the message that school is important, that is important to their present and future lives".

The urge to establish contact was also mentioned by other teachers: "We've spent the weekend calling all parents, asking for e-mails" (T1); "The concern was not to teach, but to the establish relations with students and colleagues that were suddenly cut" (T12). As coordinator of a professional course, T12 first concern was to coordinate the team of teachers so that they could start working right away and not lose contact with the students. The concern to gather contacts was present from the first moment, followed by the organisation of the teachers' team and the drawing up of a plan not to lose contact. 


\subsubsection{Dealing with privacy and exposition}

Moving to online classroom environments implied a transition to digital, an environment with specific characteristics in what concerns privacy and exposition [13].

For T1, privacy was not an issue: mentioning that being online implied less exposure than being with students in a classroom, the only concern was about her students' own loss of spontaneity and embarrassment. T2 and T3 share the same opinion, stating that "The parent's presence, although being visible, was not a problem" (T2) and that even teaching from home, "this was a natural situation, as the kitchen was the place at home where I felt more comfortable and at ease, never felt that my privacy or home space were invaded" (T3). For other teacher, privacy should not be an issue under the special conditions brought by the confinement period: "There is a trust contract between teacher and students, one that exists at school and that existed now" (T6).

This feeling was not shared by all the teachers interviewed. For some, "Teaching online was a challenge, there is a loss of privacy, as it is not possible to know who is watching on the other side" (T4). T5 mentions that "it was difficult to deal with the feeling that I was being watched by other persons than my students". Although being familiar with the computer as a teaching tool, using it a mediation tool was sometimes strange: T12 mentioned that "The computer became a curtain, almost like a stage", a feeling and a state of alertness that remained even after the end of school year. The fact that some students were not comfortable with having the camera on and then chose not to show themselves was mentioned by other teacher (T8), while in other situations there was the explicit instruction, from School, for students not to have their camera on (T10, T11).

\subsection{Main challenges faced by parents during the suspension of classroom activities}

\subsubsection{Managing personal and professional lives}

Reconciling professional and personal lives was a challenge faced during the suspension of classroom activities. In an effort to achieve a balance between working time and supporting their children child in their school tasks, labour hours were extended.

Parents started working earlier, before children were awake and school day began, and worked long before bedtime: "It was impossible not to work overtime. It was just not possible" (P1); "I've worked from sunrise until after midnight" (P3); "I worked every day from 6 a.m. to midnight or even longer, and had to work on weekends. That was the only way I could do this" (P5); "I woke up earlier, around 6 a.m., and stayed awake until pass 1 a.m." (P6); "There was the need to work overtime, because I had to compensate [my company] for the time I had to spend with the children" (P10). Parents state that this was a scenario that went from March to the end of June, which led to "a feeling of exhaustion and disorientation" (P6) that was very difficult to overcome: "by May all days seemed the same" (P3).

Most parents spent time between supporting children in school activities (P1, P5, P6, P10), work and household chores (P1, P2, P3, P6). Working from home led to a feeling of no separation between personal and family space, both in its physical and emotional dimensions (P1 to P6, P10), leading to the feeling that "my home was no longer my home" (P1). Managing several agendas, requests, commitments, and managing physical space at home were mentioned as some the main challenges experienced during the confinement period, making it hard to manage home, work and emotions: "we start with a plan, and end up with a very different day" (P4); "overlapping work and parenting was a source of stress. It changed me. I changed" (P5).

\subsubsection{Giving support to children}

The need to support their children, either pedagogically and emotionally, was also one of the dimensions that required parent's attention.

Supporting children during school tasks and homework (P1, P3, P5, P6), managing their children's effort to comply with all the tasks and homework sent by school (P1, P7), and making an effort to establish a calm and stress-free environment for their children (P1, P6, P7, P8) were some of the main goals mentioned by parents, ones which required a lot of effort and energy to deal with: "I was really concerned about their emotional balance, more than academic achievements, I wanted them to be happy and calm, to minimize the emotional impact of the confinement" (P6); "I wanted to create a stress-free environment, they were scared and afraid about everything that was going on - we all were" (P7); "Family time is always precious, and on those days it became even more important' (P8). 
In what concerns technological support (e.g. scanning and uploading homework assignments), some parents point out that their children's computer literacy was essential for the organisation of tasks: from scanning files to sending work to the teacher (P2, P4, P5, P7, P8, P9, P10), and even by exploring extracurricular tools and technologies (P2, P4, P8), children easily became autonomous and integrated the new routines into their daily activities. Some parents mentioned the need to manage equipment and internet, shared between several family members (P2, P6, P7), which in a few situations required the acquisition of additional equipment (P5, P6).

\subsubsection{Privacy and exposition}

Being unable to control the child's entrance in the digital world was also a source of anxiety for P1, as "everything was too fast, and I was not able to make the soft introduction that I intended to do". This feeling of losing control is also mentioned by P6, who stated that "suddenly they had to register in several platforms, and for me that was too soon". P7 tried to ensure that only the teacher and the children's colleagues were attending the online class, and the computer camera was turned on only during synchronous sessions.

P9 mentions that "it had to be", and that even if now the feeling that some things were rushed comes to her mind, "those were particular times with particular needs". To some parents, privacy - under these conditions and as it was a school environment - was not an issue: the only recommendation was that the child should not walk around the house with the computer camera on (P2) and to identify the best physical space for the child to work and ensure that children had all the conditions to work (P3, P5). As some teachers did not required for students to turn on the computer's webcam (P4) and web safety and privacy issues were already addressed during family conversations (P2, P8) or by the school (P10), there were no special concerns about online exposure or privacy loss.

\subsection{Discussion}

The analysis of the information collected from the interviews allowed for the identification of similarities and convergence points in interviewees' discourse. It also revealed the existence of dimensions which, not being directly related to the questions posed by the interviewer, highlighted several factors that should be consider when planning or analysing a transition to a computer-mediated teaching/learning approach.

This reflection, although still requiring a more in-depth analysis and consolidation - namely through the conduction of more interviews - led to the development of a proposal that can be considered as one starting point when analysing the educational implications of moving from face-to-face to online learning, namely for Primary and Secondary Education scenarios. The proposal is graphically represented in Figure 1.

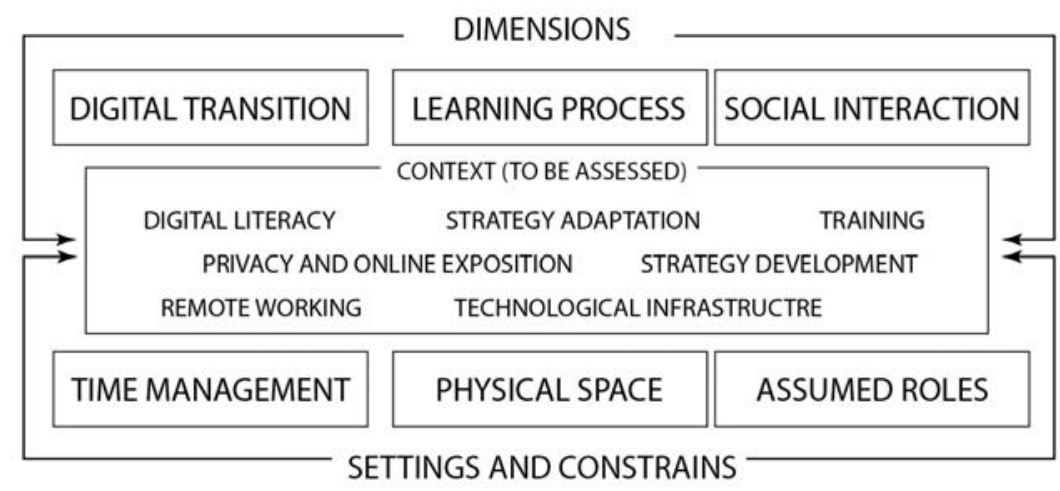

Figure 1. Relationships and dimensions in ubiquitous learning scenarios - a proposal for reflection

In this reflection proposal, it is sustained that going digital - namely in what concerns moving to online learning environments - should take into consideration three dimensions: digital transition, learning process and social interaction (e.g. replicating face-to-face interaction in online environments).

Approaching these three dimensions should not be done in an agnostic way, but always taking into account the scenarios and constraints that emerge from the transition from the physical school to the online school environment: the impact that this transition will have on teachers, students and parents 
time management, the management of physical space (e.g. living conditions) and the different roles that each involved educational agent may have to assume (e.g. parent/educator, teacher/ educator).

The definition of a strategy aiming to support digital transition that takes into account these dimensions and constraints can never ignore the need to assess and characterise the context in which each actor moves and articulates his/her life. This assessment should consider aspects such as digital literacy, the creation or adaptation of strategies, the concerns about online privacy and exposure, the need for additional training, the articulation with remote work and the technological infrastructure with which individual will have to work (e.g. internet connection, work equipment, internet access device).

\section{CONCLUSIONS}

The Covid-19 pandemic had a deep impact in the lives of individuals, with repercussions not yet fully known. Education was not spared, as the suspension of classroom activities in most countries, which last at least 10 weeks, forced teachers, parents and students to move away from face-to-face learning to an online model. This was a scenario that brought more difficulties to disadvantaged students, who had more difficulties in adjusting to distance learning [14]. Although the efforts made by the educative community to maintain learning continuity during this period, namely the creation of educative and pedagogical video content broadcasted by public televisions (e.g. "Estudo em Casa" [15]), and parent's support, students had to rely more on their own autonomy, responsibility and resources to continue learning.

The emergence of these new ubiquitous learning scenarios - characterized by the overlap and permeability of personal, professional, familiar and learning contexts - had deep implications in the life of the ones involved in the educational process (teachers, parents and students), who had to adapt, organise and reconcile the different dimensions of their lives.

This paper presents the main results of a study aiming to characterize the ubiquitous learning scenarios and challenges brought by the COVID-19 pandemic to the Portuguese Primary and Secondary Education context. Exploratory empirical research was carried out, addressing the main challenges experienced by Primary and Secondary school teachers, and parents with children in those levels of education, during the period of suspension of classroom activities. Although the study has limitations that should not be ignored, and which derive from its exploratory character, the methodological approach and the limitations of the sample, the analysis of collected data enhances that going digital required significant adjustments for both teachers and parents, with the main challenges being the (re)establishment of the relations with the students, managing family-work context, managing time, and keeping students' interest and motivation during confinement times.

\subsection{Concluding remarks}

The emerging technological phenomena, which have heightened the complexity of analogue and virtual reality, are still extensions of the human being in all its dimensions, from family, work, consumption and even memory. In this line, the cultural appropriation of the digital amplifies the better (and also the worse) side of the human being. When we reflect on technology, we thus deepen our knowledge of the human being.

The most recent change in school reality has led to an increase in the use of technologies as mediation and mentoring tools, requiring the definition of transformative skills in teaching, as well as the revision of the ethical dimension of digital literacy. Digital technologies are recognised as information and communication tools, but the power based on the management of mechanisms to control information flows does not go unnoticed. In fact, the integrability of ignorance and the future accentuates the unpredictability and uncertainty of knowledge. Knowing that teaching and learning impose different actions on the teacher and the student, the most difficult thing is to define what the teacher should not teach, so that the student discovers after having been exposed to knowledge that produces knowledge. In this tension, if technology is the extension of the human being in the accomplishment of complex tasks, where does creativity in the teaching context stand? In the dynamics about what is up to the student and what is up to the teacher, the school system configured by technology maintains the objective of feeding the passage from ignorance to knowledge. This notion, in the digital transition, entails the repercussion of the acceleration of personal and social time, without this meaning a qualitative increase in interpersonal relations or knowledge.

Not aiming to present an exhaustive or comprehensive description of all personal and professional scenarios that emerged as a result of the sudden transition to digital, this paper - and the reflection it 
proposes - tries, through the speeches of those who have experienced the challenges brought by the new reality, to unveil what was, what it is or what would be like to live in these coexisting scenarios.

\section{ACKNOWLEDGEMENTS}

The authors would like to acknowledge the support of DigiMedia - Digital Media and Interaction Research Center and CEIS20 - Centro de Estudos Interdisciplinares do Séc.XX during the course of this study. The authors would like to thank the teachers and parents who participated in this study, for all their availability and generosity.

\section{REFERENCES}

[1] L. A. Cardenas-Robledo and A. Pena-Ayala, "Ubiquitous learning: A systematic review," Telematics and Informatics, vol. 35, pp. 1097-1132, 2018.

[2] J. Munoz-Cristobal, M. Rodriguez-Trians, V. Gallego-Lema, H. Arribas.Cubero, J. Asensio-Perez and A. Martinez-Mones, "Monitoring for Awareness and Reflection in Ubiquitous Learning Environments," Int. Journal of Human-Computer Interaction, vol. 34, no. 2, pp. 146-165, 2017.

[3] S. Aljawarneh, "Reviewing and exploring innovative ubiquitous learning tools in higher education," Journal of Computing in Higher Edcation, pp. 57-73, 2020.

[4] A. A. S. Dias, P. Feliciano, A. L. Rocha, M. Neves, F. Correia, E. CArdoso and A. Goulart, "Governação \& Práticas de e-Learning em Portugal Estudo 2014," TecMinho/ Centro e-Learning, Guimarães, 2014.

[5] A. D. Dumford and A. L. Miller, "Online learning in higher education: exploring advantages and disadvantages for engagement," Journal of Computing in Higher Education, vol. 30, p. 452-465, 2018.

[6] N. livari, S. Sharma and L. Ventä-Olkkonen, "Digital transformation of everyday life - How COVID19 pandemic transformed the basic education of the young generation and why information management research should care?," International Journal of Information Management, in press.

[7] S. Jacob and S. Radhai, "Trends in ICT e-learning: Challenges and expectations," International Journal of Innovative Research \& Development, vol. 5, no. 2, pp. 196-201, 2016.

[8] A. Benavente, P. Peixoto and R. M. Gomes, "Impacto do Covid-19 no sistema de ensino português Resultados parciais a 8 de abril 2020 - parte 3," 2020a.

[9] A. Benavente, P. Peixoto and R. M. Gomes, "Impacto do Covid-19 no sistema de ensino português - resultados preliminares e parciais," Observatório das Políticas de Educação e Formação, 2020b.

[10] Nova School of Business \& Economics, "Ensino a Distância: $2^{\circ}$ Questionário a Professores," 23 maio 2020. [Online]. Available: https://tinyurl.com/y22hs3wk. [Accessed July 2020].

[11] A. Benavente, P. Peixoto and R. M. Gomes, "Impactoda Covid-19 no sistema de ensino português - análise parcial a 15 de maio 2020," 2020c.

[12] L. Bardin, L. (1977). Análise do conteúdo (L. A. R. e. A. Pinheiro1st ed.). Lisboa: Edições 70.

[13] D. Boyd, Faceted id/entity: Managing representation in a digital world, Massachusetts, Massachusetts Institute of Technology, 2002.

[14] OECD, "Education at a Glance 2020: OECD Indicators," OECD Publishing, Paris, 2020.

[15] RTP and Portuguese Republic, "Estudo em Casa," 2020. [Online]. Available: https://www.rtp.pt/play/estudoemcasa/. [Accessed 10 June 2020]. 